Article

\title{
Effect of Ag Nanoparticle Size on Ion Formation in Nanoparticle Assisted LDI MS
}

\author{
Vadym Prysiazhnyi ${ }^{1,2, *}$, Filip Dycka ${ }^{2}$, Jiri Kratochvil ${ }^{2}$, Vitezslav Stranak ${ }^{2} \mathbb{C}$ \\ and Vladimir N. Popok ${ }^{3}$ \\ 1 Faculty of Science, Masaryk University, Kamenice 5, 62500 Brno, Czech Republic \\ 2 Faculty of Science, University of South Bohemia, Branisovska 1760, 37005 Ceske Budejovice, Czech Republic; \\ fdycka@prf.jcu.cz (F.D.); jkratochvil@prf.jcu.cz (J.K.); stranak@prf.jcu.cz (V.S.) \\ 3 Department of Materials and Production, Aalborg University, Skjernvej 4A, DK-9220 Aalborg, Denmark; \\ vp@mp.aau.dk \\ * Correspondence: prysiazhnyi@mail.muni.cz
}

Received: 8 July 2020; Accepted: 19 August 2020; Published: 24 August 2020

\begin{abstract}
Metal nanoparticles (NPs) were reported as an efficient matrix for detection of small molecules using laser desorption/ionization mass spectrometry. Their pronounced efficiency is mostly in desorption enhancement, while, in some cases, NPs can facilitate charge transfer to a molecule, which has been reported for alkali metals and silver. In this work, we present the study of the influence of Ag NP size on the laser desorption/ionization mass spectra of a model analyte, the molecule of riboflavin. The NPs were produced by magnetron sputtering-based gas aggregation in a vacuum and mass-filtered before the deposition on substrates. It was found that the utilization of smaller Ag NPs (below $15 \mathrm{~nm}$ in diameter) considerably enhanced the molecule desorption. In contrast, the laser irradiation of the samples with larger NPs led to the increased ablation of silver, resulting in [analyte + $\mathrm{Ag}^{+}$adduct formation.
\end{abstract}

Keywords: silver nanoparticles; nano-PALDI MS; SALDI MS; laser desorption

\section{Introduction}

Surface enhancement employing nanomaterials in detection and imaging is implemented in many applications, including mass spectrometry [1], fluorescence imaging [2], Raman scattering [3-5], and various sensing technologies [6]. Often, the nanomaterials are prepared as nanoparticles (NPs), as there is a number of efficient production methods [7] also allowing the tailoring of the NP properties [8]. In particular, metal NPs are widely used in laser desorption/ionization mass spectrometry (LDI MS) [9]. Irradiating the samples with short laser pulses creates a plume of species (neutrals, ions, and molecules in excited states). Ionized species can be extracted and analyzed. For a few reasons, an additional component is required (the so-called matrix) that enhances the desorption and facilitates the charging of the molecules of interest [10]. Metal NPs can be such a matrix; two methods in the literature are the so-called surface-assisted LDI MS (SALDI MS) [11] and nanoparticle-assisted LDI MS (nano-PALDI MS) [12]. Two effects are typically highlighted when NPs are used as a matrix in LDI MS: local heating [13] (resulting in desorption enhancement) and high surface reactivity (which can lead to improved selectivity [14] and, thus, the increased sensitivity of the method [15]). Moreover, the matrix should provide conditions for efficient ionization [16]. Commonly, a protonation of an analyte is expected. However, a NP can also be a source of ions, which can form adducts with the molecules of interest [17].

An empirical approach was employed in the majority of studies, where nanomaterials were used as a matrix for LDI MS [18-20]. Although the reported high sensitivity and selectivity are remarkable, 
only a few works have studied the fundamental aspects of the processes leading to the enhancement. In particular, the physics of laser-nanoparticle interaction in the presence of biological tissue has been studied relatively poorly, and this is easy to explain: the system is very complex. Though a nanoparticle matrix is considered to become "hot" under a laser impulse, leading to the more frequent fragmentation of an analyte, it also allows ionizing molecules that are not typically ionized using other matrix types [21,22]. The cationization of analytes was investigated, mostly focusing on alkali metals, as those form single charged ions [23,24]. In particular, a competition between different cationization agents on the riboflavin molecule was investigated [25]. In many cases [26-28], the charge transfer process was studied in metal salts or nanostructured surfaces. The conclusions of that research are not directly transferrable to NP-based matrices.

Silver is known as an element that efficiently forms adducts with different analytes [17]. This is related to the close proximity of the localized surface plasmon resonance (LSPR) wavelengths of Ag NPs to the typical laser wavelengths used in LDI MS devices and, thus, to an efficient energy transfer from the laser to the NPs [29]. For example, in our previous work, we showed that gas-aggregated Ag NPs have an adsorption maximum at $367 \mathrm{~nm}$, while one of the commonly used laser wavelengths in MALDI devices is $355 \mathrm{~nm}$ [30]. We reported that use of large Ag NPs (32 $\pm 6 \mathrm{~nm}$ in diameter) led to a formation of adducts between small molecules and silver atoms. However, there were no studies on the NP size and its impact on ion formation and MALDI efficiency. Moreover, the application of small-size Ag NPs (below $10 \mathrm{~nm}$ ) is intensively exploited for the detection of small molecules $[30,31]$ and mass spectrometry imaging [32,33], demonstrating the enhancement of a signal $[M+H]^{+}$ion in the most cases, where $M$ denotes the molecule of interest. Even though a formation of $[M+A g]^{+}$ ions was observed for certain molecules, the underlying physical processes were not investigated. The current study addresses two issues regarding the effect of NP size: i) the ion formation of a small-molecular-weight analyte; ii) the material release from NPs and adduct formation with the analyte molecule.

\section{Materials and Methods}

The substrate choice was confined by conditions for the time-of-flight (TOF) MS. It was necessary to have relatively small-sized, thin, conductive-from-both-sides, and flexible substrates, which would not superinduce additional ions in the mass spectra. The substrates were made of $0.1 \mathrm{~mm}$-thick polyethylene terephthalate (PET) sheets. Plastic sheets were cut into $12 \times 12 \mathrm{~mm}$ pieces, cleaned in isopropanol, and dried in air. The $250 \mathrm{~nm}$-thick $\mathrm{Cu}$ film was deposited on each side in a custom-made vacuum system equipped with a 2" water-cooled magnetron with a $\mathrm{Cu}$ target. The film thickness was measured using an AlphaStep D-500 profilometer from KLA Tencor. The sputtering was carried out using Ar under $4 \mathrm{~Pa}$ of pressure and an applied current of $150 \mathrm{~mA}$ (DC power, $43 \mathrm{~W}$ ).

Riboflavin $\left(\mathrm{C}_{17} \mathrm{H}_{20} \mathrm{~N}_{4} \mathrm{O}_{6}\right.$; molecular weight, $376.37 \mathrm{~g} / \mathrm{mol}$; p.a. grade) was used as a model molecule. The molecule contains a flavin group, representing importance for medical applications [34], and, as mentioned above, was used in similar studies. While a common approach to depositing an analyte onto the substrate is droplet crystallization, our preliminary tests showed that it results in the low reproducibility of MS in terms of both ion composition and absolute intensity. We relate this with the non-homogeneous analyte crystallization and coffee-ring effects [35]. Instead, a fine riboflavin powder was sprinkled over the substrate surface. We refer, by "fine powder", to microparticles that had a submillimeter diameter. By doing this, we were able to perform laser shots on the riboflavin surface, avoiding the necessity of dealing with crystallization issues. The substrates were placed into the vacuum chamber, where the NPs were deposited as described below, stabilizing the powder on the surface.

Silver NPs were produced using a commercial nanocluster source (NC200U from Oxford Applied Research) attached to the custom-built vacuum system, which, together with the source, was called MaSCA [36]. The particles were formed by the magnetron sputtering of a silver target (99.99\% purity) and aggregation of the sputtered material in a vacuum. The NPs were collimated into a beam and 
mass-filtered prior to deposition using an electrostatic quadrupole mass selector, providing standard deviations of the particle diameters within 10\% [37]. After the size selection, the NPs were deposited on the $\mathrm{Cu} / \mathrm{PET}$ substrates in a soft-landing regime [38]. More details about the MaSCA and operation conditions can be found elsewhere [39]. For the current experiments, the NPs were filtered at voltages 200, 500, 700, 1100, and $1600 \mathrm{~V}$. The chosen range of voltages defining the particle sizes (diameters) was based on the best sustainability for the deposition of mass-filtered NPs. The beam currents and deposition times were controlled in order to obtain the same surface coverage of NPs for every filtering voltage, $(3 \pm 1) \cdot 10^{11} \mathrm{~cm}^{-2}$.

The deposited NPs were studied by atomic force microscopy (AFM) using a Ntegra Aura system (from NT-MDT). Commercial Si cantilevers with a tip curvature radius $\leq 10 \mathrm{~nm}$ were employed. It was found that the copper films on the PET substrates had a nanogranular structure with relatively high roughness (root mean square, RMS $=11.5 \mathrm{~nm}$ ), as can be seen in Figure 1. Such surface morphology made it difficult to distinguish the deposited nanometer-scale particles. Therefore, the NPs were also deposited in parallel on smooth Si substrates (RMS $<0.5 \mathrm{~nm}$ ), which were used for the size analysis.

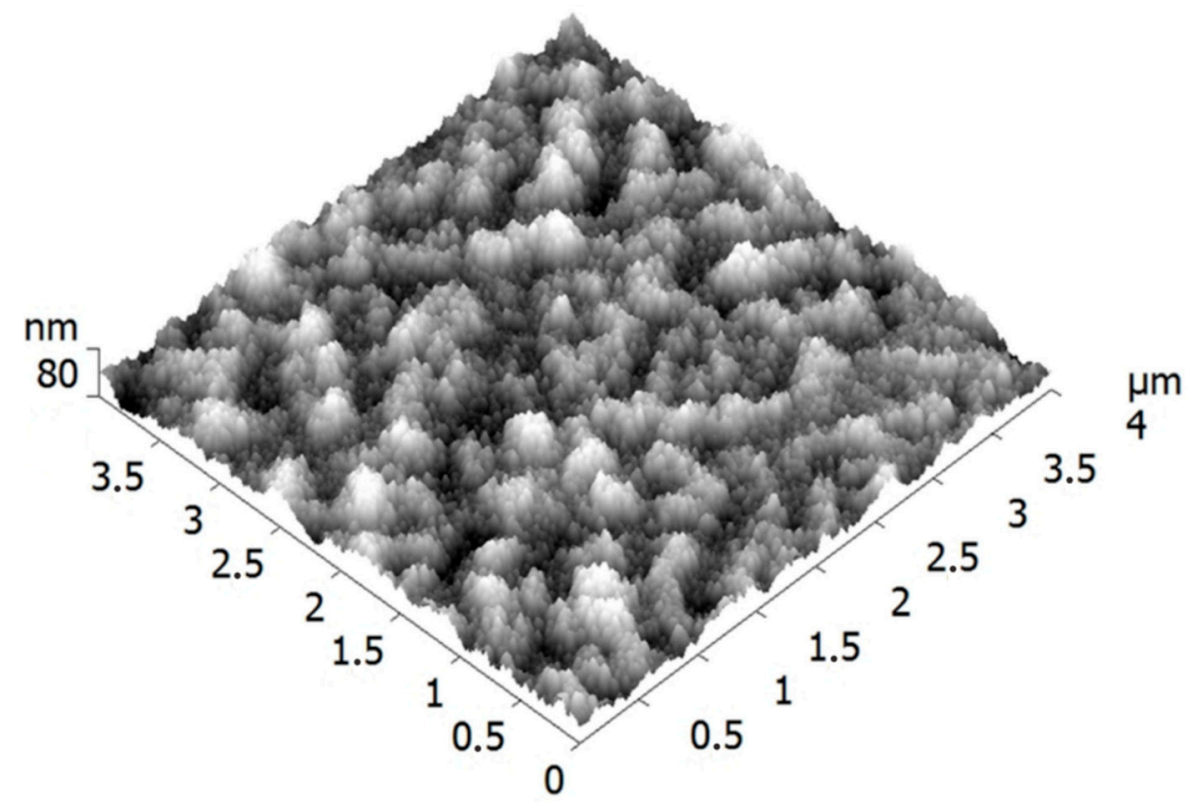

Figure 1. Atomic force microscopy (AFM) image of the copper film deposited on polyethylene terephthalate (PET).

For the LDI MS, the prepared samples were placed on ITO-covered glass using double-sided carbon tape and positioned on an MTP Slide Adapter II from Bruker. Mass spectra were acquired in the positive reflector ion mode using pulsed extraction with an extraction voltage of $16.3 \mathrm{kV}$, an acceleration voltage of $19 \mathrm{kV}$, a reflector voltage of $21 \mathrm{kV}$, a lens voltage of $8.3 \mathrm{kV}$, and a delayed extraction time of $130 \mathrm{~ns}$ on an autoflex ${ }^{\mathrm{TM}}$ speed mass spectrometer (from Bruker Daltonics). The laser was a Nd:YAG laser generating the third harmonic with a $355 \mathrm{~nm}$ wavelength. It produced pulses of $3 \mathrm{~ns}$ with an up to $2 \mathrm{kHz}$ repetition rate. A single spectrum was acquired as an accumulation of 500 shots with a random walk pattern. Mass spectra were calibrated on silver ions (from 100 to $970 \mathrm{Da}$ ). Further processing was performed using the mMass software.

\section{Results}

\subsection{Nanoparticle Characterization}

An AFM image of a sample with NPs filtered at $200 \mathrm{~V}$ and deposited on the Si substrate is shown in Figure 2. The corresponding height histogram yields a mean value of $10.2 \pm 1.0 \mathrm{~nm}$. The height measurements were also carried for the particles deposited after filtering at 500, 700, 1100, and $1600 \mathrm{~V}$ 
(see Figures S1-S4 in Supplementary Materials). The particles filtered at adjacent voltages-for example, 500 and 700 or 700 and $1100 \mathrm{~V}$ - have a slight overlap in sizes due to the standard deviations. However, small voltage steps allowing the fine tuning (increase) of NP size can be essential for judging the role of NP diameter. These data are summarized in Table 1 . The obtained values are in good agreement with the results previously published for NP size selection in MaSCA [34]. It is worth mentioning that silver NPs soft-landed in MaSCA typically retain their almost spherical shape; they only slightly oblate [40]. Thus, the AFM measurements of the particle heights can be a good estimate for the mean diameter/size. The particles filtered at 200, 500, 700, 1100, and $1600 \mathrm{~V}$ will be further referred to as 10 , 15, 17, 20, and $23 \mathrm{~nm}$ NPs.

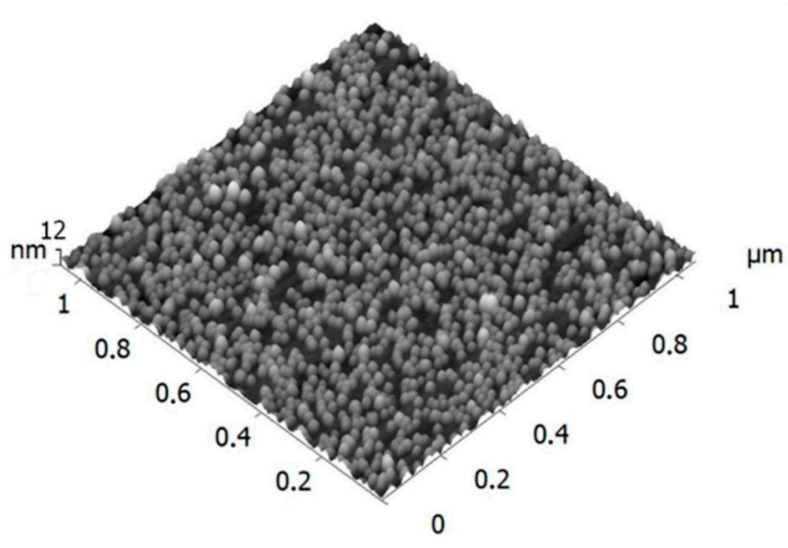

(a)

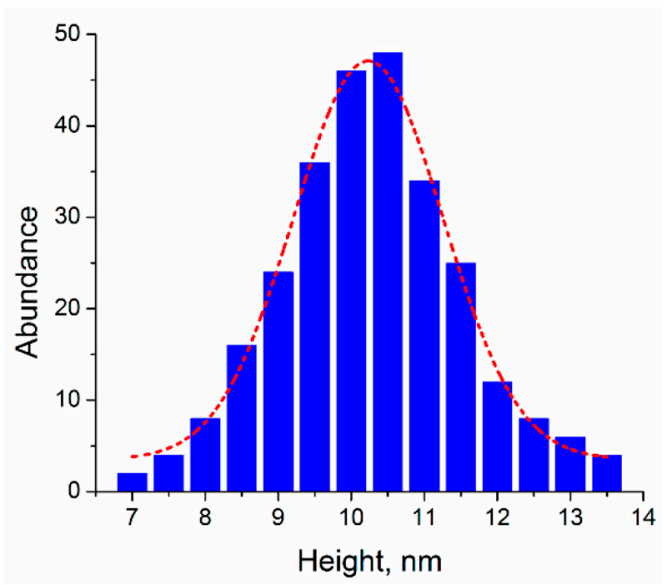

(b)

Figure 2. (a) AFM image and (b) height distribution of deposited Ag nanoparticles (NPs) filtered at $200 \mathrm{~V}$.

Table 1. Mean values with standard deviations as obtained from AFM measurements for sizes of Ag NPs filtered at different voltages.

\begin{tabular}{cccccc}
\hline Filtering Voltage, V & $\mathbf{2 0 0}$ & $\mathbf{5 0 0}$ & $\mathbf{7 0 0}$ & $\mathbf{1 1 0 0}$ & $\mathbf{1 6 0 0}$ \\
\hline NP height, $\mathrm{nm}$ & $10.2 \pm 1.0$ & $14.6 \pm 1.4$ & $17.1 \pm 1.6$ & $19.5 \pm 2.0$ & $23.3 \pm 2.4$ \\
\hline
\end{tabular}

\subsection{Riboflavin Fragmentation}

The riboflavin molecule consists of dimethyl isoalloxazine with an attached ribitol sugar. Figure 3 shows its molecular structure, highlighting possible bond cleavage spots. Two fragments with molecular weights of 242 (denoted as R1) and $135 \mathrm{~g} / \mathrm{mol}$ (as R2) are observed in the mass spectra prepared with different matrices and under LDI mode, as the cleavage of the $\mathrm{C}-\mathrm{N}$ bond comes up at lower laser fluence [41]. The cleavage of $\mathrm{C}-\mathrm{C}$ bonds in ribitol sugar under higher laser fluence results in the appearance of charged fragments: adducts between the riboflavin molecule, its R1 part, cleaved parts of ribitol sugar $\left(\mathrm{CH}_{2}, \mathrm{CH}_{2} \mathrm{COH}_{2}\right.$, etc.), and $\mathrm{Ag}$ atoms. The mass spectra of riboflavin covered with Ag NPs have ions grouped into three categories. The first one is the silver clusters $\mathrm{Ag}_{n}{ }^{+}$ ( $n \leq 9)$. The intensities of $\mathrm{Ag}^{+}, \mathrm{Ag}_{2}{ }^{+}$, and $\mathrm{Ag}_{3}{ }^{+}$ions are found to be stable (within $10 \%$ error) for each measured mass spectrum, resulting in a ratio of 1:1.3:2.3, respectively. Silver clusters of larger size were detected irregularly, having low counts compared to those of $\mathrm{Ag}^{+}$. The second category is the ions containing riboflavin molecules $(M)$ (here and below, $\mathrm{M}$ refers to the riboflavin molecule), namely, $[\mathrm{M}+\mathrm{H}]^{+},[\mathrm{M}+\mathrm{Na}]^{+},\left[\mathrm{M}+\mathrm{Ag}^{+},\left[\mathrm{M}+\mathrm{CH}_{2} \mathrm{OH}+\mathrm{H}^{+}\right.\right.$, and $\left[\mathrm{M}+\mathrm{CH}_{2}+\mathrm{Ag}^{+}\right.$. The third category of ions is the adducts formed with fragments of riboflavin (with $\mathrm{H}, \mathrm{Na}$, or $\mathrm{Ag}$ ). Table 2 summarizes the experimental ion patterns and attributed molecular components. The observed ions were taken from a few randomly selected mass spectra for samples covered with NPs of different sizes, while it should be noted that the increase in laser energy and NP size led to the appearance of higher ion variety. 
The attribution is based on the mass/charge ratio $(\mathrm{m} / \mathrm{z})$, possible chemical structure, and isotopic pattern (modeled in mMass based on the chemical formula). The difference between the experimental and theoretical values is related to the spectrometer resolution. The typical full width at half maximum (FWHM) of the detected peaks is found between 0.1 and $0.4 \mathrm{Da}$, depending on the counts for particular ion. The intensity of the given mass peaks depends on the laser fluence and NP sizes. These effects are discussed below.

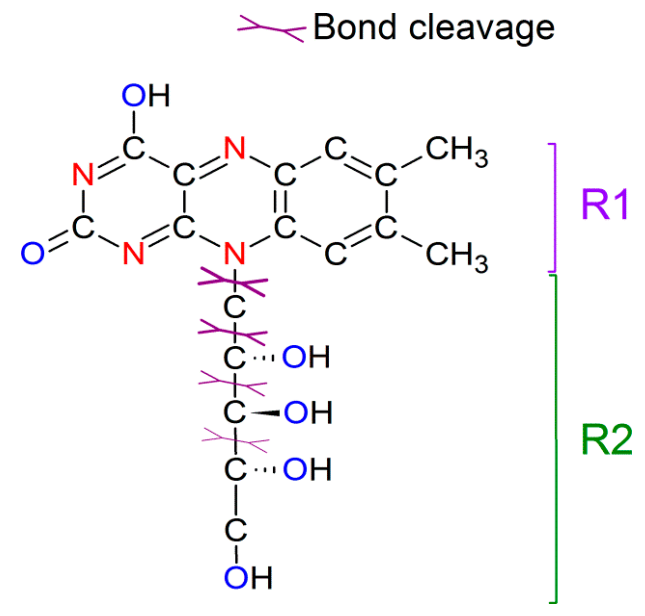

Figure 3. Structure of the riboflavin molecule with scheme of its fragmentation under laser irradiation.

Table 2. Attributed ions observed in the mass spectra of riboflavin covered by Ag NPs.

\begin{tabular}{|c|c|c|c|}
\hline Attributed Structure & Experimental $\mathrm{m} / \mathrm{z}$ & Theoretical $\mathrm{m} / \mathrm{z}$ & Formula \\
\hline $\mathrm{R} 2+\left(\mathrm{CH}_{2}\right)+\mathrm{Na}$ & 172.07 & 172.07 & $\mathrm{C}_{6} \mathrm{H}_{13} \mathrm{O}_{4} \mathrm{Na}$ \\
\hline $\mathrm{R} 2+\left(\mathrm{CH}_{2}\right)_{2}+\mathrm{H}$ & 186.06 & 186.08 & $\mathrm{C}_{7} \mathrm{H}_{15} \mathrm{O}_{4} \mathrm{Na}$ \\
\hline$A g_{2}+H$ & 216.80 & 216.81 & $\mathrm{Ag}_{2} \mathrm{H}$ \\
\hline$R 2+A g$ & 241.81 & 241.97 & $\mathrm{C}_{5} \mathrm{H}_{11} \mathrm{O}_{4} \mathrm{Ag}$ \\
\hline$R 1+\stackrel{\circ}{H}$ & 243.07 & 243.08 & $\mathrm{C}_{12} \mathrm{H}_{11} \mathrm{~N}_{4} \mathrm{O}_{2}$ \\
\hline $\mathrm{R} 2+\mathrm{CH}_{2}-\mathrm{H}+\mathrm{Ag}$ & 254.91 & 254.97 & $\mathrm{C}_{6} \mathrm{H}_{12} \mathrm{O}_{4} \mathrm{Ag}$ \\
\hline $\mathrm{R} 1+\mathrm{CH}_{2}+\mathrm{H}^{\circ}$ & 257.09 & 257.10 & $\mathrm{C}_{13} \mathrm{H}_{13} \mathrm{~N}_{4} \mathrm{O}_{2}$ \\
\hline$R 1+A g$ & 348.96 & 348.98 & $\mathrm{C}_{12} \mathrm{H}_{10} \mathrm{~N}_{4} \mathrm{O}_{2} \mathrm{Ag}$ \\
\hline $\mathrm{R} 1+\mathrm{CH}_{2}+\mathrm{Ag}$ & 362.97 & 363.00 & $\mathrm{C}_{13} \mathrm{H}_{12} \mathrm{~N}_{4} \mathrm{O}_{2} \mathrm{Ag}$ \\
\hline$M+H$ & 377.07 & 377.15 & $\mathrm{C}_{17} \mathrm{H}_{21} \mathrm{~N}_{4} \mathrm{O}_{6}$ \\
\hline$M+N a$ & 399.07 & 399.12 & $\mathrm{C}_{17} \mathrm{H}_{20} \mathrm{~N}_{4} \mathrm{O}_{6} \mathrm{Na}$ \\
\hline $\mathrm{R} 1+\mathrm{C}_{4} \mathrm{H}_{10} \mathrm{O}_{2}+\mathrm{Ag}$ & 439.00 & 439.05 & $\mathrm{C}_{16} \mathrm{H}_{20} \mathrm{~N}_{4} \mathrm{O}_{4} \mathrm{Ag}$ \\
\hline$R 1+A g_{2}$ & 457.83 & 457.89 & $\mathrm{C}_{12} \mathrm{H}_{10} \mathrm{~N}_{4} \mathrm{O}_{2} \mathrm{Ag}_{2}$ \\
\hline$M+A g$ & 482.94 & 483.04 & $\mathrm{C}_{17} \mathrm{H}_{20} \mathrm{~N}_{4} \mathrm{O}_{6} \mathrm{Ag}$ \\
\hline $\mathrm{M}+\mathrm{CH}_{2}-\mathrm{H}+\mathrm{Ag}$ & 497.03 & 497.05 & $\mathrm{C}_{18} \mathrm{H}_{22} \mathrm{~N}_{4} \mathrm{O}_{6} \mathrm{Ag}$ \\
\hline
\end{tabular}

\subsection{Effect of Laser Fluence and NP Size on Mass Spectra of Riboflavin}

The effect of laser fluence on the obtained mass spectra is shown in Figure 4. Note that laser fluence is calculated as a percentage of the total laser power (TLP), the only parameter provided by the TOF MS manufacturer. The lower fluence limit is determined by the threshold above which the number of generated ions start prevailing over the instrumental noise ( $40 \%$ of the TLP in our case) [42]. The upper fluence limit is related to the phenomenon of electrostatic repulsion in the ion cloud, causing $\mathrm{m} / \mathrm{z}$ shifts, an increase in the FWHM, and signal distortion [43]. In our case, these effects become drastic when the fluence approaches $55 \%$ of the TLP.

At the lowest used laser fluence, the mass spectrum contains only protonated riboflavin, its protonated fragments, and $\left[\mathrm{M}+\mathrm{Ag}^{+}\right.$ions of relatively low intensity. The absence of $\mathrm{Ag}_{n}{ }^{+}$ clusters and their adducts means that the transferred energy is not sufficient to eject $\mathrm{Ag}$ atoms from the 
NPs. The abovementioned clusters, as well as silver ions, and adducts with riboflavin/fragments start appearing at higher fluences.

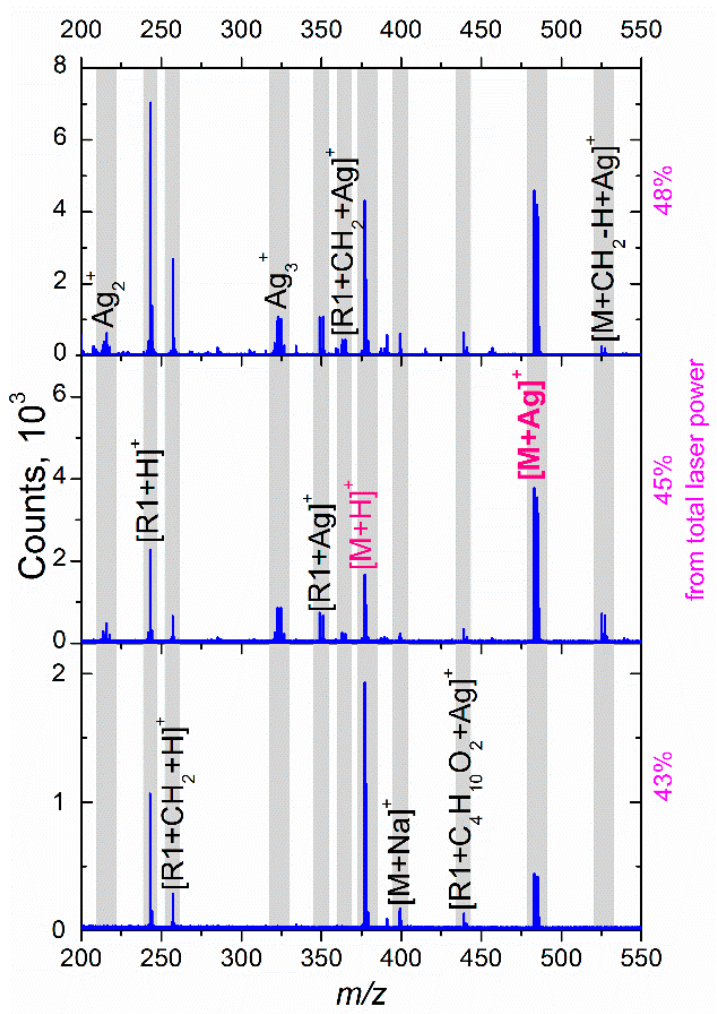

Figure 4. The effect of laser fluence on the mass spectra of riboflavin for the case of $10 \mathrm{~nm} \mathrm{Ag} \mathrm{NPs.}$

Figure 5 shows the differences in the mass spectra for riboflavin covered with 10, 15, 17, and $23 \mathrm{~nm}$ Ag NPs (all the graphs have the same $y$-scale). In this case, the sample was irradiated with a fluence equivalent to $43 \%$ of the TLP. In the obtained spectra, one can see two main tendencies: (i) the intensity of protonated ions (for example, $[\mathrm{R} 1+\mathrm{H}]^{+}$and $[\mathrm{M}+\mathrm{H}]^{+}$) changes insignificantly with an increase in the particle size, while (ii) the ion counts related to silver clusters and adducts increase drastically for the cases of larger NPs. Two effects can be attributed to the observed phenomena: an increased interaction cross-section for the NPs of larger diameter (and, as a result, higher laser energy absorption) [44], and enhanced optical extinction due to the LSPR of Ag NPs [38,45]. Thus, the laser power transferred to an NP causes heating and a strong local electromagnetic field; both effects can facilitate the ejection of atoms or even small clusters. According to the Mie theory, the absorption cross-section depends on the cube of the particle radius [46]. Thus, one can suppose that for the smallest NPs, the absorbed energy is lower than a threshold value required for the ejection, while with the particle size increase, an ejection of ions and small clusters becomes possible, as can be seen in Figure 5. Since the thermal and electromagnetic phenomena interact for a metal NP in a sophisticated manner, the abovementioned hypothesis requires further study going beyond the goals of the current paper.

The integration of the measured signal obtained from the full isotopic pattern of a single molecule provides a value proportional to the number of generated ions. Based on the relative simplicity of our system (monomolecular sample and size-selected NPs), we can collect mass spectra of similar intensity from different samples and, thus, analyze the changes in ion counts through the absolute values of areas for the isotopic patterns. After initial data filtering (the removal of artifacts and mass spectra with low total ion counts), it is possible to compare the most prominent attributed structures depending on both the laser fluence and silver NP size. The results of the data evaluation are presented in Figure 6. The first important conclusion is that the absolute intensity of protonated riboflavin is independent (within errors) of the Ag NP size, while it increases with the laser fluence. We observe a slight decrease 
in $[\mathrm{M}+\mathrm{H}]^{+}$ion counts only for the highest laser fluences, which can be related to the significant increase in $\mathrm{Ag}$ ion intensity and consequent suppression effects [47]. The signal of $\mathrm{Ag}^{+}$shows the same tendency to increase with particle size for all laser fluences, although the intensity values are higher for the higher fluences, which is well understood; higher power transfer leads to a higher level of material ablation. An important finding is that the NPs should be above a certain "threshold size" (around $15 \mathrm{~nm}$ in our case) to promote the materials' release, which is already discussed above (see Figure 5). This "threshold size" is also evident for the formation of $[M+A g]^{+}$ions. Within the errors of the experiments, the intensity of this signal does not considerably depend on either NP size or laser fluence.

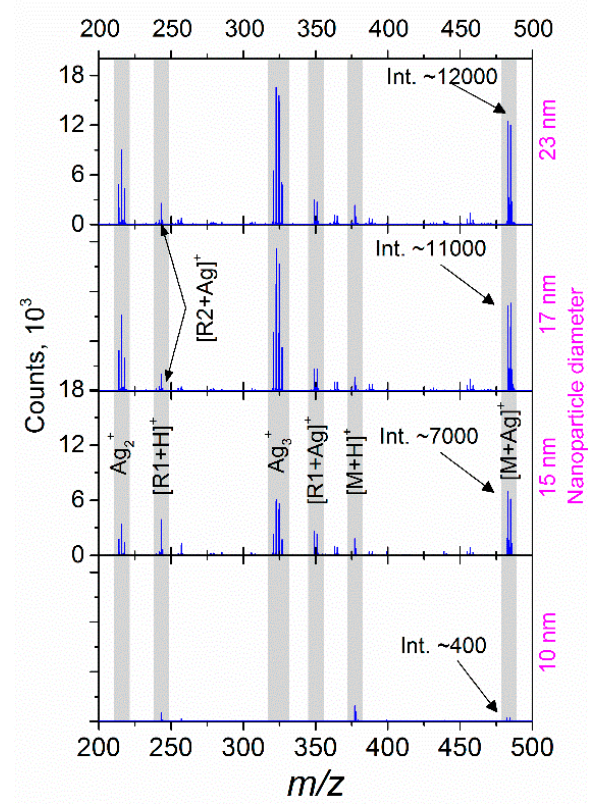

Figure 5. The effect of NP size on mass spectra of riboflavin for laser fluence equivalent to $43 \%$ of total laser power.

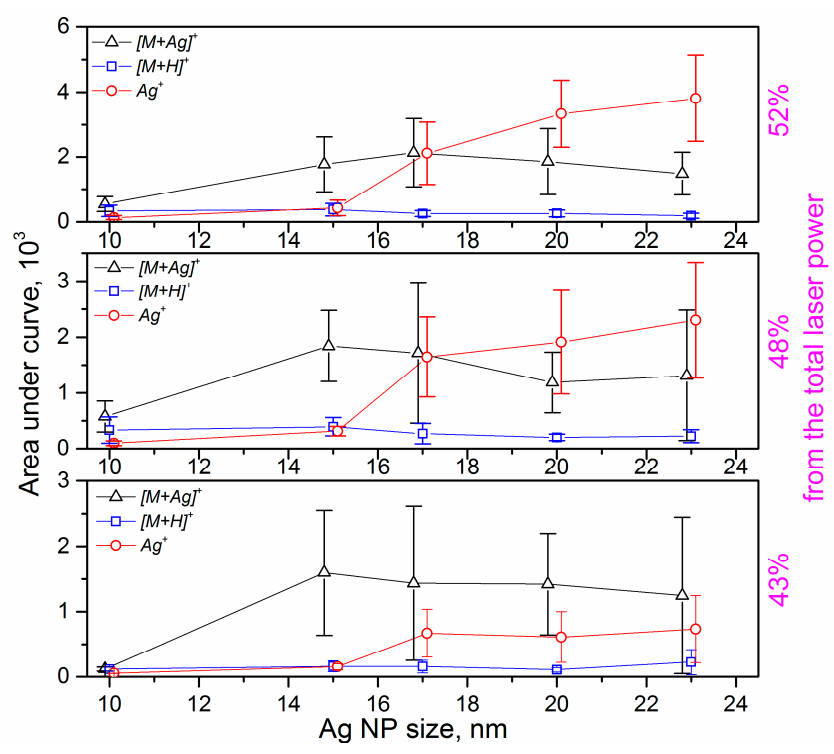

Figure 6. Comparison of absolute ion intensity for the selected ions as a function of Ag NP size for $43 \%$ and $48 \%$ of total laser power (TLP). Data points corresponding to the given NP sizes are intentionally slightly shifted on the $x$-axis for better visualization. 
Figure 7 shows the ratio between the intensities for $\left[\mathrm{M}+\mathrm{Ag}^{+}\right.$and $\mathrm{Ag}^{+}$ions for different laser fluences and NP sizes. It can be seen that for the lowest laser fluence and smallest NPs, the energy transfer is not enough to cause any considerable release of $[M+A g]^{+}$ions. For the higher fluences, the observed tendencies are the same concerning the particle size. The release of the silver ions is higher for the higher values of the laser fluence, and it has the same trend for the larger NPs. As for the ablated silver ions, it is evident that the utilization of NPs as a matrix would require the proper optimization of the material quantity (NP surface coverage) together with the laser fluence. For the proper measurement, the intensity of the silver ions should not significantly exceed the $[M+A g]^{+}$intensity. For example, for the TLP of $43 \%$, the silver ion counts do not exceed those of the riboflavin/silver ions (see Figure 6). Meanwhile, for the TLP of 52\%, the quantity of silver ions released from $17 \mathrm{~nm}$ NPs is equal to that of $[M+A g]^{+}$.

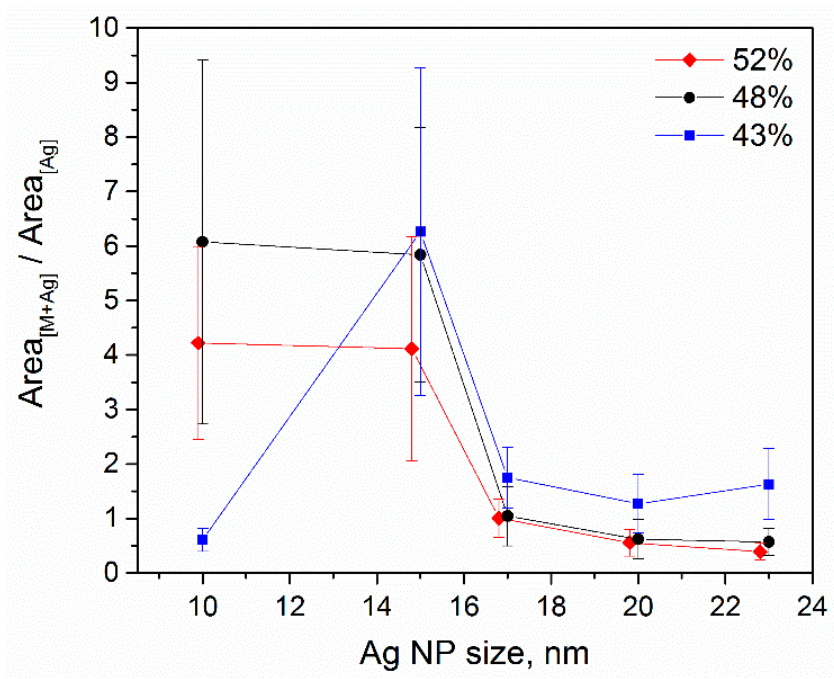

Figure 7. The ratio between $[\mathrm{M}+\mathrm{Ag}]^{+}$and $\mathrm{Ag}^{+}$ion intensities depending on the Ag NP size and laser fluence.

\section{Conclusions}

Size-selected Ag NPs were prepared using the gas aggregation of magnetron-sputtered Ag and deposited on the substrates with the model analyte, riboflavin, in order to study the efficiency of NPs as a matrix for enhancing nano-PALDI MS. It has been shown that the release of Ag atoms, clusters, and ions from the NP surface and the formation of Ag adducts with the analyte molecule strongly depend on the NP size and laser fluence. Our study revealed that the silver release under the laser irradiation is insignificant for small NPs. However, it considerably increases for the particles with sizes $\geq 15 \mathrm{~nm}$ : silver ions and small charged silver clusters become the dominant species in the spectra. It is suggested that the particle heating and formation of a strong electromagnetic field (due to LSPR) upon interaction with laser light could be the main factors affecting the materials' release. The presence of metal ions in the plume triggers the formation of adducts with riboflavin and its fragments. In order to use the adduct ions for molecular detection, a proper amount of NP material in the matrix (requiring the adjustment of the NP size and surface coverage) should be used. One can also conclude that the use of matrices with large silver NPs could allow the investigation of other cationization agents.

Supplementary Materials: The following are available online at http://www.mdpi.com/2673-3501/1/1/2/s1. Figure S1: (a) AFM image and (b) height distribution of deposited Ag NPs filtered at 500 V; Figure S2: (a) AFM image and (b) height distribution of deposited Ag NPs filtered at $700 \mathrm{~V}$; Figure S3: (a) AFM image and (b) height distribution of deposited Ag NPs filtered at 1100 V; Figure S4: (a) AFM image and (b) height distribution of deposited Ag NPs filtered at $1600 \mathrm{~V}$.

Author Contributions: Conceptualization: V.P. and J.K.; data acquisition: V.P., F.D., and V.N.P.; data processing, V.P., F.D., J.K., and V.N.P.; original draft preparation, V.P.; review and editing, V.N.P., F.D., J.K., and V.S.; supervision, V.S.; All authors have read and agreed to the published version of the manuscript. 
Funding: V.P. acknowledges the financial support from the Czech Science Foundation through the project GACR 19-20927Y and financial support from the Standard Trainership Erasmus+ program for staff mobility. F.D. was supported from the European Regional Development Fund-Project "Mechanisms and dynamics of macromolecular complexes: from single molecules to cells" (No. CZ.02.1.01/0.0/0.0/15_003/0000441). J.K. was supported from TAČR GAMA-2 TP01010019. V.S. acknowledges the financial support from the Czech Science Foundation through the project GACR 19-20168S.

Acknowledgments: The authors acknowledge Antonin Bednarik for fruitful discussions on the MS data analysis.

Conflicts of Interest: The authors declare no conflict of interest. The funders had no role in the design of the study; in the collection, analyses, or interpretation of data; in the writing of the manuscript; or in the decision to publish the results.

\section{References}

1. Lei, C.; Qian, K.; Noonan, O.; Nouwens, A.; Yu, C. Applications of nanomaterials in mass spectrometry analysis. Nanoscale 2013, 5, 12033-12042. [CrossRef]

2. Keshavarz, M.; Tan, B.; Venkatakrishnan, K. Multiplex photoluminescent silicon nanoprobe for diagnostic bioimaging and intracellular analysis. Adv. Sci. 2018, 5, 1700548. [CrossRef]

3. Camden, J.P.; Dieringer, J.A.; Wang, Y.; Masiello, D.J.; Marks, L.D.; Schatz, G.C.; van Duyne, R.P. Probing the structure of single-molecule surface-enhanced Raman scattering hot spots. J. Am. Chem. Soc. 2008, 130, 12616-12617. [CrossRef] [PubMed]

4. Keshavarz, M.; Kassanos, P.; Tan, B.; Venkatakrishnan, K. Metal-oxide surface-enhanced Raman biosensor template towards point-of-care EGFR detection and cancer diagnostics. Nanoscale Horiz. 2020, 130, $294-307$. [CrossRef]

5. Keshavarz, M.; Tan, B.; Venkatakrishnan, K. Label-free sers quantum semiconductor probe for molecular-level and in vitro cellular detection: A noble-metal-free methodology. ACS Appl. Mater. Interfaces 2018, 10, 34886-34904. [CrossRef] [PubMed]

6. Zeng, S.; Baillargeat, D.; Ho, H.P.; Yong, K.T. Nanomaterials enhanced surface plasmon resonance for biological and chemical sensing applications. Chem. Soc. Rev. 2014, 43, 3426-3452. [CrossRef]

7. Tsuzuki, T. Commercial scale production of inorganic nanoparticles. Int. J. Nanotechnol. 2009, 6, 567-588. [CrossRef]

8. Liz-Marzán, L.M. Tailoring surface plasmons through the morphology and assembly of metal nanoparticles. Langmuir 2006, 22, 32-41. [CrossRef]

9. Abdelhamid, H.N. Nanoparticle assisted laser desorption/ionization mass spectrometry for small molecule analytes. Microchim. Acta 2018, 185, 200. [CrossRef]

10. Gemperline, E.; Rawson, S.; Li, L. Optimization and comparison of multiple MALDI matrix application methods for small molecule mass spectrometric imaging. Anal. Chem. 2014, 86, 10030-10035. [CrossRef]

11. Tanaka, K.; Waki, H.; Ido, Y.; Akita, S.; Yoshida, Y.; Yoshida, T. Protein and polymer analyses up to m/z 100 000 by laser ionization time-of-flight mass spectrometry. Rapid Commun. Mass Spectrom. 1988, 2, 151-153. [CrossRef]

12. Taira, S.; Sugiura, Y.; Moritake, S.; Shimma, S.; Ichiyanagi, Y.; Setou, M. Nanoparticle-assisted laser desorption/ionization based mass imaging with cellular resolution. Anal. Chem. 2008, 80, 4761-4766. [CrossRef] [PubMed]

13. Boerigter, C.; Aslam, U.; Linic, S. Mechanism of Charge Transfer from Plasmonic Nanostructures to Chemically Attached Materials. ACS Nano 2016, 10, 6108-6115. [CrossRef] [PubMed]

14. Kailasa, S.K.; Wu, H.F. One-pot synthesis of dopamine dithiocarbamate functionalized gold nanoparticles for quantitative analysis of small molecules and phosphopeptides in SALDI- and MALDI-MS. Analyst 2012, 137, 1629-1638. [CrossRef]

15. Iwaki, Y.; Kawasaki, H.; Arakawa, R. Human serum albumin-modified $\mathrm{Fe}_{3} \mathrm{O}_{4}$ magnetic nanoparticles for affinity-SALDI-MS of small-molecule drugs in biological liquids. Anal. Sci. 2012, 28, 893-900. [CrossRef] [PubMed]

16. Zenobi, R.; Knochenmuss, R. Ion formation in MALDI mass spectrometry. Mass Spectrom. Rev. 2002, 17, 337-366. [CrossRef]

17. Lai, E.P.C.; Owega, S.; Kulczycki, R. Time-of-flight mass spectrometry of bioorganic molecules by laser ablation of silver thin film substrates and particles. J. Mass Spectrom. 1998, 33, 554-564. [CrossRef] 
18. Teng, C.H.; Ho, K.C.; Lin, Y.S.; Chen, Y.C. Gold nonoparticles as selective and concentrating probes for samples in MALDI MS analysis. Anal. Chem. 2004, 76, 4337-4342. [CrossRef]

19. Dong, X.; Cheng, J.; Li, J.; Wang, Y. Graphene as a novel matrix for the analysis of small molecules by MALDI-TOF MS. Anal. Chem. 2010, 82, 6208-6214. [CrossRef]

20. Jiang, D.; Song, N.; Li, X.; Ma, J.; Jia, Q. Highly selective enrichment of phosphopeptides by on-chip indium oxide functionalized magnetic nanoparticles coupled with MALDI-TOF MS. Proteomics 2017, 17, 17-18. [CrossRef]

21. Lu, M.; Yang, X.; Yang, Y.; Qin, P.; Wu, X.; Cai, Z. Nanomaterials as Assisted Matrix of Laser Desorption/Ionization Time-of-Flight Mass Spectrometry for the Analysis of Small Molecules. Nanomaterials 2017, 7, 87. [CrossRef]

22. Jackson, S.N.; Baldwin, K.; Muller, L.; Womack, V.M.; Schultz, J.A.; Balaban, C.; Woods, A.S. Imaging of lipids in rat heart by MALDI-MS with silver nanoparticles. Anal. Bioanal. Chem. 2014, 406, 1377-1386. [CrossRef]

23. Goolsby, B.J.; Brodbelt, J.S.; Adou, E.; Blanda, M. Determination of alkali metal ion binding selectivities of calixarenes by matrix-assisted laser desorption ionization and electrospray ionization in a quadrupole ion trap. Int. J. Mass Spectrom. 1999, 193, 197-204. [CrossRef]

24. Hortal, A.R.; Hurtado, P.; Martínez-Haya, B.A.; Arregui, L. Bañares, Solvent-free MALDI investigation of the cationization of linear polyethers with alkali metals. J. Phys. Chem. B 2008, 112, 8530-8535. [CrossRef]

25. Yang, S.; Shi, Y.; Ma, Y.; Mu, L.; Kong, X. Competition between metal cationization and protonation/reduction in MALDI process: An example of riboflavin. Int. J. Mass Spectrom. 2018, 434, 209-214. [CrossRef]

26. Knochenmuss, R.; Dubois, F.; Dale, M.J.; Zenobi, R. The matrix suppression effect and ionization mechanisms in matrix-assisted laser desorption/ionization. Rapid Commun. Mass Spectrom. 1996, 10, 871-877. [CrossRef]

27. Wong, C.K.L.; Dominic Chan, T.-W. Cationization processes in matrix-assisted laser desorption/ionization mass spectrometry: Attachment of divalent and trivalent metal ions. Rapid Commun. Mass Spectrom. 1997, 11, 513-519. [CrossRef]

28. Montaudo, G.; Montaudo, M.S.; Puglisi, C.; Samperi, F.; Sepulchre, M. End-group characterization of poly(methylphenylsilane) by alkali metal salts doped MALDI-TOF mass spectra. Macromol. Chem. Phys. 1996, 197, 2615-2625. [CrossRef]

29. Wu, S.; Qian, L.; Huang, L.; Sun, X.; Su, H.; Gurav, D.D.; Jiang, M.; Cai, W.; Qian, K. A Plasmonic mass spectrometry approach for detection of small nutrients and toxins. Nano-Micro Lett. 2018, 10, 52. [CrossRef]

30. Prysiazhnyi, V.; Dycka, F.; Kratochvil, J.; Sterba, J.; Stranak, V. Gas-aggregated Ag nanoparticles for detection of small molecules using LDI MS. Anal. Bioanal. Chem. 2020, 412, 1037-1047. [CrossRef]

31. Sekuła, J.; Nizioł, J.; Rode, W.; Ruman, T. Silver nanostructures in laser desorption/ionization mass spectrometry and mass spectrometry imaging. Analyst 2015, 140, 6195-6209. [CrossRef] [PubMed]

32. Muller, L.; Baldwin, K.; Barbacci, D.C.; Jackson, S.N.; Roux, A.; Balaban, C.D.; Brinson, B.E.; McCully, M.I.; Lewis, E.K.; Schultz, J.A.; et al. Laser Desorption/Ionization Mass Spectrometric Imaging of Endogenous Lipids from Rat Brain Tissue Implanted with Silver Nanoparticles. J. Am. Soc. Mass Spectrom. 2017, 28, 1716-1728. [CrossRef] [PubMed]

33. Zhang, Z.; Li, S.; Liu, J.; Liu, L.; Yang, H.; Zhang, Y.; Wang, T.; Zhao, Z. Silver nanoparticles as matrix for MALDI FTICR MS profiling and imaging of diverse lipids in brain. Talanta 2018, 179, 624-631. [CrossRef]

34. Beztsinna, N.; Tsvetkova, Y.; Jose, J.; Rhourri-Frih, B.; al Rawashdeh, W.; Lammers, T.; Kiessling, F.; Bestel, I. Photoacoustic imaging of tumor targeting with riboflavin-functionalized theranostic nanocarriers. Int. J. Nanomed. 2017, 12, 3813-3825. [CrossRef] [PubMed]

35. Hu, J.B.; Chen, Y.C.; Urban, P.L. Coffee-ring effects in laser desorption/ionization mass spectrometry. Anal. Chim. Acta. 2013, 766, 77-82. [CrossRef]

36. Hanif, M.; Popok, V.N. Magnetron Sputtering Cluster Apparatus for Formation and Deposition of Size-Selected Metal Nanoparticles. In Physics, Chemistry and Applications of Nanostructures; Borisenko, V.E., Gaponenko, S.V., Gurin, V.S., Kam, C.H., Eds.; World Sci. Publ.: Singapore, 2015; pp. 416-419.

37. Hanif, M.; Juluri, R.R.; Chirumamilla, M.; Popok, V.N. Poly(methyl methacrylate) composites with size-selected silver nanoparticles fabricated using cluster beam technique. J. Polym. Sci. Part. B Polym. Phys. 2016, 54, 1152-1159. [CrossRef]

38. Popok, V. Energetic Cluster-Surface Collisions. In Handbook of Nanophysics: Clusters and Fullerenes; Sattler, K.D., Ed.; CRC Press: Boca Raton, CA, USA, 2010; pp. 19-1-19-19. 
39. Popok, V.N.; Gurevich, L. Charge states of size-selected silver nanoparticles produced by magnetron sputtering. J. Nanoparticle Res. 2019, 21, 171. [CrossRef]

40. Novikov, S.M.; Popok, V.N.; Evlyukhin, A.B.; Hanif, M.; Morgen, P.; Fiutowski, J.; Beermann, J.; Rubahn, H.-G.; Bozhevolnyi, S.I. Highly-stable monocrystalline silver clusters for plasmonic applications. Langmuir 2017, 33, 6062-6070. [CrossRef]

41. McMahon, J.M. The analyses of six common vitamins by laser desorption mass spectroscopy. Anal. Biochem. 1985, 147, 535-545. [CrossRef]

42. Spengler, B.; Bahr, U.; Karas, M.; Hillenkamp, F. Postionization of laser-desorbed organic and inorganic compounds in a time of flight mass spectrometer. Instrum. Sci. Technol. 1988, 17, 173-193. [CrossRef]

43. Ingendoh, A.; Karas, M.; Hillenkamp, F.; Giessmann, U. Factors affecting the resolution in matrix-assisted laser desorption-ionization mass spectrometry. Int. J. Mass Spectrom. Ion Process. 1994, 131, 345-354. [CrossRef]

44. Govorov, A.O.; Richardson, H.H. Generating heat with metal nanoparticles. Nano Today 2007, 2, 30-38. [CrossRef]

45. González, A.L.; Noguez, C.; Beránek, J.; Barnard, A.S. Size, shape, stability, and color of plasmonic silver nanoparticles. J. Phys. Chem. C 2014, 118, 9128-9136. [CrossRef]

46. Hlaing, M.; Gebear-Eigzabher, B.; Roa, A.; Marcano, A.; Radu, D.; Lai, C.Y. Absorption and scattering cross-section extinction values of silver nanoparticles. Opt. Mater. 2016, 58, 439-444. [CrossRef]

47. Chandler, J.; Haslam, C.; Hardy, N.; Leveridge, M.; Marshall, P. A Systematic Investigation of the Best Buffers for Use in Screening by MALDI-Mass Spectrometry. SLAS Discov. 2017, 22, 1262-1269. [CrossRef]

(C) 2020 by the authors. Licensee MDPI, Basel, Switzerland. This article is an open access article distributed under the terms and conditions of the Creative Commons Attribution (CC BY) license (http://creativecommons.org/licenses/by/4.0/). 